\title{
Movilizaciones patrióticas y crisis política: La Liga Patriótica, Argentina 1898
}

\author{
Patriotic mobilizations and political crisis: Liga Patriótica. Argentine, 1898
}

\author{
Ana Leonor Romero \\ aleonoromero@yahoo.com.ar \\ Universidad de Buenos Aires, Argentina
}

Recepción: 17 Julio 2020

Aprobación: 17 Septiembre 2020

Publicación: 13 Noviembre 2020

Cita sugerida: Romero, A. L. (2020). Movilizaciones patrióticas y crisis política: La Liga Patriótica, Argentina 1898. Anuario del Instituto de Historia Argentina, 20(2), e124. https://doi.org/10.24215/2314257Xe124
Resumen: En octubre de 1898, Julio A. Roca comenzó su segunda administración. Su imagen estaba asociada a la idea de orden. En los meses anteriores se había exacerbado el conflicto fronterizo entre la Argentina y Chile, y el peligro de una guerra fue determinante en la elección de una persona considerada más adecuada para presidir el gobierno en esas circunstancias. En los meses anteriores a su asunción se organizó la Liga Patriótica, que movilizó una parte importante de la ciudadanía e inició un debate sobre el significado del patriotismo como valor político. Este artículo analiza el papel de la Liga Patriótica y se propone demostrar que este momento fue considerado por los contemporáneos como una coyuntura crítica y no como el de un retorno al orden. Considera que la movilización de la ciudadanía, impulsada por el patriotismo, fue la respuesta a esta situación crítica y reflexiona sobre sus efectos políticos.

Palabras clave: Movilización, Patriotismo, Crisis, Roca, Política.

Abstract: In October 1898, Julio A. Roca started his second administration. His image was associated with the idea of order. The previous months were characterized by the exacerbation of the boundary conflict between Argentina and Chile and the possibility of war was crucial in Roca's election because his image was associated with the notion of order so he was considered the right person to be in power. During these months Liga Patriótica, a civil association that mobilized a large part of the citizenship, was organized. Its intervention in the public sphere triggered a debate about the role of citizenship and the meaning of patriotism as a political value. This article aims to analyze the role of Liga Patriótica to demonstrate that this moment was considered by the contemporaries as a critical one and not as a return to order. It also argues that the mobilization driven by patriotism, was a response to this critical situation and ponders its political effects.

Keywords: Mobilization, Patriotism, Crisis, Roca, Politics. 


\section{INTRODUCCIÓN}

En octubre de 1898 Julio A. Roca inició su segunda presidencia. El camino a este triunfo estuvo dado por la creencia de que él sería el que pudiera superar la situación interna y externa -el peligro de la reaparición de los alzamientos revolucionarios del primer quinquenio de la década y el clima bélico con Chile-, y por la asociación de su figura con la idea de orden, con lo que perfiló un conjunto de expectativas sobre su futura administración (Ferrari, 1968).

Esta asociación entre la idea de orden y las presidencias de Roca ha dominado, con algunas excepciones, la perspectiva historiográfica sobre el período. ${ }^{1}$ Así, su primera gestión -entre 1880 y 1886 - es considerada como la inauguración de un período con un nuevo ordenamiento político, articulado por el Partido Autonomista Nacional y caracterizado por la disminución de la conflictividad armada y por haber establecido las condiciones para la expansión económica (Alonso, 1997). En esta secuencia, la Revolución del Parque y la crisis económica de 1890 habrían impugnado este sistema que, luego de este cimbronazo, habría continuado -aunque con cuestionamientos- su lógica hasta la primera década del siglo XX. En esta versión, la segunda presidencia de Roca es el remanso de la crisis que inauguró la década del noventa, un momento de recuperación del orden. Algunos trabajos han comenzado a desarmar esta idea mostrando los aspectos conflictivos de su segundo gobierno (Romero, 2008; Romero, 2018). Como señala Inés Rojkind (2012, 2017), a lo largo de su presidencia se desarrolló una política contestataria en la que la calle fue el espacio para expresar opiniones y articular reclamos que preocupaban a la opinión pública. De las distintas preocupaciones que atravesaron el debate público en el fin de siglo, dos movilizaron profundamente a la opinión en 1898: la situación de la economía, en especial de las finanzas, ${ }^{2}$ y la posibilidad de una guerra con Chile.

La propuesta de este artículo es analizar la coyuntura de la elección y de la asunción de Roca en 1898 tomando como eje una preocupación que atravesó fuertemente el debate público ese año, la posibilidad de una guerra con Chile, para evaluar el conjunto de expectativas previas a su segundo mandato. El argumento que guía este trabajo es demostrar que ese momento fue leído por los contemporáneos en clave de crisis y no de recuperación del orden. En la misma línea, considera la movilización de la sociedad impulsada por el patriotismo como una respuesta elaborada por la ciudadanía frente a esta situación crítica, que demostró tener gran potencial político.

La cuestión limítrofe con Chile se convirtió, a lo largo del verano de 1898, en una preocupación central de la opinión pública. El protocolo de demarcación de 1896 había establecido la opción por el arbitraje externo si en los trabajos de demarcación no se solucionaban las divergencias entre los peritos. ${ }^{3}$ De acuerdo con ello, en mayo de 1898, cuando surgieron las divergencias, se estableció que en agosto los peritos debían reunirse en Santiago de Chile para terminar de acordar el criterio de demarcación limítrofe. Los peritos no se pusieron de acuerdo. Siguieron días de tensión y alerta pública, ya que si no se adoptaba el arbitraje la otra opción era la guerra y el gobierno no había adelantado su postura frente a esa disyuntiva. Finalmente, a fin de septiembre, días antes de la asunción presidencial de Julio A. Roca, se firmó un tratado que acordaba el arbitraje. Al mismo tiempo, la economía presentaba algunos signos de recesión: déficit fiscal -producto del pago de deudas y del gasto en armamento e instrucción militar, necesarios para competir en la carrera armamentista con Chile-, una moneda sobrevaluada, una retracción en el mercado de capitales y problemas en las cosechas, ocasionados por la langosta. ${ }^{4}$

Ambas cuestiones, la situación de la economía y el peligro de guerra, afectaban cómo era valorada una nación. El modo en que el gobierno de cada país resolvía sus conflictos internacionales ponía en juego dos cuestiones centrales: su capacidad de legitimar internamente esa decisión y el posicionamiento de esa nación en el escenario mundial. La prensa cumplió, en todo el mundo, un papel activo en la creación de este clima de conflicto y movilización pública de finales del siglo XIX $^{5}$ - como en la guerra hispanonorteamericana ${ }^{6}$ y fomentó algunas lecturas globales del problema de la guerra que ampliaron una 
reflexión sobre el papel de la movilización patriótica en los conflictos. Esta dinámica dio lugar a una mayor presencia pública de movimientos ciudadanos que, conformados frente a los distintos conflictos nacionales, mostraron la potencialidad de movilización e intervención del patriotismo en la política interna (Mosse, 2007). A fin de siglo, la disputa por cómo concebir la nación informó el debate global y mostró la tensión entre dos modelos. Uno, articulado por la idea de integración, denominado cosmopolita por sus adversarios, que entendía la participación política en términos representativos. Otro, de exclusión y partidario de la homogeneidad cultural, que se asociaba a una democracia sustancial o verdadera. ${ }^{7}$

Frecuentemente, este debate sobre la noción de patriotismo ha sido abordado desde su aspecto identitario, vinculado a cuestiones como el nacionalismo y la definición de la ciudadanía, y al desarrollo de dinámicas de identificación de grupos y de inclusión y exclusión. Sin dejar de reconocer la importancia de estos debates ya abordados por la historiografía, este artículo propone recuperar otro aspecto político de la disputa por su significado: el tipo de intervención política que, inspirada por esta noción, se llevó a cabo. En ese sentido, se considera el patriotismo como un valor, que orientó el comportamiento de los actores, definió relaciones y dio sentido a las acciones de quienes lo enarbolaban para intervenir en la esfera pública. ${ }^{8}$ Así, este trabajo trata de pensar la articulación entre las formas de intervenir en la esfera pública y los modos de entender la nación.

En la Argentina, con motivo de la exacerbación del conflicto, se originó un movimiento, agrupado en la Liga Patriótica, ${ }^{9}$ que movilizó a gran parte de la ciudadanía y puso en el centro del debate el significado del patriotismo como valor político y el papel de esta frente a una situación crítica. A partir de esas cuestiones, en este artículo se analizan, en primer lugar, las polémicas en la prensa sobre las características de la movilización ciudadana en los meses previos a la elección de Roca y las propuestas que surgieron, y luego se examinan las características de la organización de la Liga Patriótica. En segundo lugar, se explora, desde esta perspectiva, el clima de movilización y crisis que rodeó la elección y asunción de Roca. Finalmente, se analiza la tensión que generó la firma de los tratados de septiembre, pocos días antes de la asunción de Roca, para evaluar límites y alcances de la movilización patriótica.

\section{LA OPINIÓN SE MOVILIZA}

Durante el verano de 1897-1898, la publicación de un informe del perito argentino Francisco Moreno, Reconocimiento de la región andina de la República Argentina: apuntes preliminares sobre una excursión del Neuquén, Rio Negro, Chubut y Santa Cruz, ${ }^{10}$ reanimó el clima de enfrentamiento con Chile. La prensa chilena -El Chileno, El Porvenir, La Ley y La Tarde-consideró que con esa publicación mostraba un sesgo que lo inhabilitaba como perito y debía ser retirado de las negociaciones. Moreno había señalado lo inadecuado del criterio de la divisoria de aguas, sostenido por la diplomacia chilena, ya que los cursos de los ríos eran modificables. Así, para finales de enero se realizaron meetings de protesta en todo Chile (Espinosa Moraga, 1958; Yujnovsky, 2011). La agitada crítica contra Moreno fue contestada por los diarios argentinos, en particular La Prensa, que estableció posiciones, convocó a la opinión a movilizarse en favor de esa causa y reclamó al gobierno políticas de acción. ${ }^{11}$ En cambio, otros periódicos, como La Nación, ${ }^{12}$ encontraron que esta "prensa belicosa" era un elemento que excitaba "calculadamente las pasiones" para "llevar las hostilidades a remolque” (La Nación, 5/5/1898). Como lo caracterizó Carlos Pellegrini en carta a Miguel Cané, el asunto chileno era una "nueva 'fermentación' de prensa". ${ }^{13}$

A medida que crecía este enfrentamiento con Chile surgieron de la sociedad civil argentina distintas iniciativas para apoyar la causa. Tres nacieron al calor del incidente creado por la publicación del libro del Perito Moreno: la compra de un buque de guerra, la formación de la Liga Patriótica y una suscripción nacional. Las reacciones fueron diversas y combinaron entusiasmo y escepticismo. Las iniciativas revelaron la potencialidad de la movilización patriótica y evidenciaron la falta de acuerdo sobre cómo debía juzgarse este fenómeno y sobre qué valores debían asociarse al patriotismo. Para finales de siglo, la cultura de 
la movilización formaba parte del arco de opciones con las que la ciudadanía manifestaba su opinión y peticionaba al gobierno. La aparición de voces que daban cuenta de la diversidad de intereses y opiniones de la sociedad complejizó el modo en que éstas eran valoradas, por su potencial desafío al orden pero también porque manifestaban la tensión entre la unidad de la opinión y la presencia de intereses particulares en la esfera pública. ${ }^{14}$

La propuesta de La Prensa y de algunos jóvenes entusiastas, a fines de enero, de un meeting de apoyo y recepción al Perito Moreno que regresaba de Chile evidenció las opiniones encontradas de este debate. La Nación censuró desde un principio su tono belicoso (La Nación, 8/1/1898), aplaudió cuando la juventud modificó su plan por una salutación en la casa del Perito (La Nación, 1/2/1898) y llamó a calmar los espíritus. Esta ambigüedad en la prensa exteriorizaba un desacuerdo sobre las dimensiones que debían tomar estas declaraciones, sobre qué implicaba poner en marcha una iniciativa patriótica y, fundamentalmente, sobre los inconvenientes y ventajas que generaban la movilización de la ciudadanía en relación con el orden político. Durante estos meses de fervor patriótico, La Nación siguió condenando aquellas "manifestaciones empeñadas en volver sobre incidentes solucionados, y de las críticas que se escuchan con motivo de trabajos que se supone tendentes a llegar a una pronta terminación de la cuestión de límites con la república de Chile" (La Nación, 16/5/ 1898). Su línea editorial -que coincidió con periódicos como La Voz de la Iglesia- ${ }^{15}$ restringía el lugar de la manifestación pública y marcaba un límite al papel del patriotismo como movilizador de la ciudadanía, pues consideraba que, fuera de sus cauces, era "una estéril o perjudicial agitación en el vacío que transformaba las energías en estorbos” (La Nación, 16/5/1898).

Una segunda propuesta surgió en Tucumán: organizar una suscripción nacional para comprar una nave y así completar la flota nacional. Fue mejor recibida. El modelo de patriotismo asociado a la compra de un buque de guerra y no a la protesta callejera ya había dado pruebas de efectividad y baja conflictividad: había sido el procedimiento elegido por la colectividad española en la Argentina en 1896, al estallar el conflicto en Cuba. La Asociación Patriótica Española había optado con buen resultado por este emblema una suscripción para comprar un buque de guerra para España en su guerra en Cuba- para presentarse en el espacio público argentino (Romero, 2007). ${ }^{16}$ Así lo habían juzgado La Voz de la Iglesia y La Nación al señalar que el patriotismo español era la oportunidad para mostrar la grandeza de la nación, que "prevalecerá sobre las pasiones y aspiraciones personales" (La Nación, 9/8/1897). Probablemente por ese motivo, la propuesta de la suscripción para el barco fue recibida finalmente como una "inspiración del sentimiento nacional", que reunió “todos los gremios y clases sociales" (La Nación, 4/3/1898).

La Nación se plegó a la campaña nacional, que "encuentra en todas partes la misma acogida entusiasta, agitando al país entero con un sentimiento unánime que habla bien alto en favor del patriotismo argentino" (La Nación, 7/3/1898), y le destinó una sección permanente, "Movimiento patriótico", en sus páginas (La Nación, 9/3/1898). La campaña de alcance nacional estableció una comisión patriótica central auspiciada por el Club Gimnasia y Esgrima de Buenos Aires (Bertoni, 2001, p. 239) e incluyó la participación activa de personalidades del mundo político como Dardo Rocha. ${ }^{17}$ Fue presidida por Antonio Del Pino (los presidentes honorarios eran Julio A. Roca, Bartolomé Mitre, Luis Sáenz Peña, Bernardo Irigoyen y Carlos Pellegrini). ${ }^{18}$ Esta propuesta se completó con una suscripción interna nacida de un círculo de personas del comercio, que logró recaudar aproximadamente 35.800.000 pesos en un mes. ${ }^{19}$

En estas iniciativas, los efectos polémicos de la movilización patriótica, como la perturbación del orden, quedaban casi rezagados y resultaron opciones potables para definir un patriotismo que se presentaba activo pero no combativo. Sin embargo, este consenso se fracturó en marzo de 1898 cuando surgió una nueva propuesta: la conformación de una Liga Patriótica.

A fines de marzo circuló una invitación, reproducida en todos los periódicos, para constituir una Liga Patriótica como la de todas las naciones "civilizadas, entre ellas España, en donde ha realizado prodigios dignos de su gran temple nacional, y los Estados Unidos, donde existen asociaciones privadas especiales como 
la que tiene por misión cuidar el culto de la bandera patria" (La Prensa, 28/3/1898). A principios de abril quedó conformada la Liga Patriótica, con sus objetivos y autoridades. ${ }^{20}$

La Liga Patriótica se propuso darle sentido y proyección al patriotismo "con objeto de avivar el espíritu nacional” pero también se atribuyó un rol político: funcionar de mediador entre una opinión pública "siempre vigilante" y el gobierno para "robustecer la censura del pueblo como medio de corregir o estimular la gestión gubernativa en los actos que se refieran a la defensa nacional”. La Liga se planteó encarnar el patriotismo al "estudiar las cuestiones que afecten la integridad de la nación y divulgar sus conclusiones en todo el país por los más amplios medios de publicidad" (La Nación, 3/4/1898). Así, el patriotismo era asociado a la defensa nacional y a lo que la Liga llamó la "inspiración militar del ciudadano" (La Nación, 3/4/1898).

Algunos leyeron este emprendimiento como una causa que evidenciaba una crisis política, para la cual la movilización de la sociedad se presentaba como solución, ya que daba unidad a la sociedad. Así, crisis, causa patriótica y movilización fueron entendidas como una secuencia en la que cada elemento se encadenaba necesariamente con el otro. Otros, más cautelosos frente a lo que podían implicar las movilizaciones, como el núcleo político que se congregaba alrededor de La Nación, cuestionaron el papel político de la Liga. En principio este grupo puso en duda la efectividad de la causa patriótica como instrumento para reunir a la opinión, por ser "demasiado abstracto para que pueda reunir en su alrededor el concurso de todos los partidos que aspira; y seguramente daría pie a divergencias de aplicación y de juicio tan pronto como se quisiera hacer efectivo". Además, consideraba que la finalidad de esta propuesta era armar "un partido militante, de oposición, definida y declarada, y que esto no debía identificarse con una agrupación que aspira a tener la personería nacional, sin diferencias de matices partidistas" (La Nación, 18/5/1898). Sectores como los que convocaba La Voz de la Iglesia se sumaron a esta posición, pregonando cautela cuando antes habían convocado a la imitación del ejemplo español. Diferenciaron el accionar en el caso español, señalando que "una asociación patriótica, dentro de la misma patria, es algo menos acertado" y quitaron trascendencia a los trabajos: “¿Qué va a hacer esa liga, qué va a preparar, que no esté ya previsto por el instinto y el sentimiento de la nacionalidad?" (La Voz de la Iglesia, 21/5/1898). Otros sectores, vinculados al Partido Socialista, condenaron, como señaló Francisco Reyes (2018), estas formas de exaltación del patriotismo.

En cambio, para aquellos que defendían la importancia de la movilización cívica, entre los cuales La Prensa llevaba la voz cantante, la preocupación por la defensa nacional se convirtió en un motivo para activar y aunar la opinión (Rojkind, 2019; Lacoste, 2001). La Liga Patriótica se presentaba como el canal a través del cual impulsar la virtud cívica adormecida (La Prensa, 17/5/1898). El periódico se dedicó a la propaganda y defensa de esta asociación y de sus objetivos; publicó sus actividades, le dedicó editoriales justificando su existencia y, sobre todo, la presentó como una reacción frente al peligro. Así delineó un horizonte de crisis frente al cual proponía la solución patriótica, de la cual se presentaba como vocero. Para sus participantes, la Liga Patriótica "encarnaba perfectamente estas ideas de reacción” (La Nación, 18/5/1898).

\section{Patriotismos de guerra: la Liga Patriótica}

De los distintos emprendimientos patrióticos surgidos al calor del enfrentamiento con Chile, la Liga Patriótica fue el más polémico y el que quizá sintetiza mejor el clima de efervescencia, tensión y ansiedad que rodeó los meses anteriores a la elección de Roca.

Su organización formal -renovación de autoridades y creación de una estructura interna centralizada cuya cabeza era la Junta Ejecutiva, que debía aprobar la acción de las comisiones en los distintos espacios (La Prensa, 3/6/1898)- permitió consolidar un arco político de respaldo. Se enviaron invitaciones para formar parte de las autoridades de la Liga, principalmente como vocales de la Junta y de las seccionales, a personalidades como Dardo Rocha ${ }^{21}$-quien había participado de otras empresas similares, como la suscripción patriótica-, y se incorporaron a su dirección otras como Pedro Agote, Roque Sáenz Peña, 
Estanislao Zeballos y Manuel A. Montes de Oca. ${ }^{22}$ Esta ampliación le otorgó mayor presencia pública y la alejó de los propósitos más politizados que habían rodeado los debates en torno a su fundación. Con estos miembros de la elite cultural y política, como José María Ramos Mejía, se sumaron redes relacionadas con el mundo católico -como las de Emilio Lamarca, Pedro Agote o Roque Sáenz Peña-, con la política -como la de Dardo Rocha- y con la profesión médica -como la de Lagarde.

Poco después de su fundación, y respondiendo a un suelto en "un diario de la tarde" en el que se la asociaba con un proyecto partidario, se presentó a la Junta Ejecutiva una propuesta para declarar públicamente el único fin de la Liga Patriótica "levantar el espíritu patriótico de los ciudadanos en general de la república y propender a la instrucción de ellos en el manejo de las armas adaptadas al ejército de línea" (La Nación, 7/7/1898). Así, la dirección se alejó definitivamente de aquellas discusiones sobre su posible rol político. Esta opción por un patriotismo apolítico, sin partido, no era original; otras asociaciones de este tenor, como la Asociación Patriótica Española, habían optado por una postura similar para legitimar su presencia en la esfera pública, evitar rupturas internas y ser aprobadas por el gobierno y, en el caso de los españoles, obtener el aval de la Corona (Romero, 2007).

Siguiendo esta línea, las actividades de la Liga se orientaron sobre todo a mejorar la eficiencia del Ejército (Castro, 2012, pp. 59-63; Reyes y Bacolla, 2018, p. 208), principalmente de la Guardia Nacional. Su proyecto más resonante fue la determinación de impulsar "la instalación de polígonos de tiro en toda la República. La Liga Patriótica propiciará la fundación de institutos de esta clase en las diversas provincias, cooperando a facilitar los elementos que su instalación exige" (La Prensa, 14/6/1898). Esta medida buscaba mejorar el manejo de las armas -en particular de los nuevos Mauser modelo argentino- ${ }^{23}$ por parte de los ciudadanos, complementando los ejercicios doctrinarios de las Guardias Nacionales, de modo que su preparación "sirva para el caso en que sus servicios sean requeridos en el ejército nacional” (La Nación, 1/7/1898). Así, una parte importante de su actividad estuvo dedicada a gestionar las armas necesarias para la práctica de tiro: canalizó pedidos de armas al gobierno, comisionó agentes, como lo hizo el subcomité de Baradero con Romeo G. Gatmank (La Nación, 1/7/1898), y se entrevistó con el ministro de Guerra y Marina y con el jefe de Estado Mayor. En otros casos, como el subcomité de San Pedro, costeó la construcción de polígonos (La Nación, 7/7/1898). A la vez, envió una nota circular a los gobernadores de provincia señalando la coincidencia de intereses y propósitos entre la Liga y el Gobierno. Recomendaba la "fundación de polígonos en las cercanías de cada capital" y pedía a los gobernadores que procuraran la cesión temporaria de los terrenos por parte de los propietarios (La Nación, 11/7/1898). Como lo expresó Roque Sáenz Peña -quien fue comisionado para enviar esta circular-, "conseguiría seguramente la remisión de las armas y la correspondiente dotación de tiros para estos ejercicios”, estos podrían ser dirigidos por oficiales del ejército a cuya responsabilidad quedaba el armamento y "cuando ello no fuera posible la junta financiaría por el concurso público la dotación de las municiones y las armas" ${ }^{24} \mathrm{~A}$ esta circular respondieron rápidamente los gobernadores de La Rioja y San Luis; otros, como el de Córdoba, comunicaron que ya tenían las instalaciones necesarias.

La Liga buscó también constituirse en intermediaria de los reclamos al gobierno nacional relacionados con el estado de las Fuerzas Armadas en todo el territorio. Elevó demandas de estudio de ingeniería militar en distintas provincias, o pedidos de dinero de las provincias al gobierno nacional para la instrucción, ${ }^{25} \mathrm{e}$ investigó las denuncias sobre el estado de los cuarteles. ${ }^{26}$ También promovió la fundación de un cuerpo de caballería, que fue denominado "Regimiento Voluntario de Granaderos a Caballo". ${ }^{27}$

La preocupación por cómo activar la Guardia Nacional había atravesado todo el conflicto. Se discutió en el Congreso la penalización de las inasistencias y la reglamentación adecuada de las excepciones (Congreso Nacional/Diputados, 1898, pp. 69-70), y desde la prensa se la criticó por su falta de deber patriótico que "ni la propaganda periodística, ni las circunstancias excepcionales" (La Nación, 21/9/1898) habían modificado. La misma Liga elaboró una proclama dirigida a la Guardia Nacional, exhortándola al cumplimiento de sus deberes (La Nación, 26/7/1898). Sin embargo, la preocupación por cómo activar el cumplimiento del deber 
patriótico tropezaba con el temor por los excesos de militarización ${ }^{28}$ y por la posibilidad de que la alta movilización patriótica pudiera afectar el orden.

\section{EXPECTATIVA y CRisis EN LOS MESES PREVIOS A Roca}

La elección de Roca en julio de 1898 no calmó la preocupación con respecto a la guerra, y la situación económica la exacerbó. El imaginario del sacrificio patriótico entrelazó las preocupaciones por la posible guerra y las dificultades de la economía. Se movilizaron planes de activación económica. Varios miembros notables de la elite organizaron un empréstito interno y el gobierno, por su parte, propuso un proyecto de recorte para reducir el Presupuesto entre un 10 y un $20 \%$, argumentando que era necesario hacer frente a las "causas extraordinarias" que demandaban "un aumento de esos esfuerzos y de esos sacrificios". ${ }^{29}$ Estos dos temas se retroalimentaron y son cruciales para entender el clima de decepción que rodeó el inicio de la segunda presidencia de Roca.

Los meses anteriores a su asunción estuvieron marcados por la pregunta de si podría cumplir con la promesa de reconstrucción del orden político y económico. Ambas, piezas fundamentales del respaldo político de Roca, ocuparon un lugar central en la polémica previa a su asunción, cuando se buscó que definiera su posicionamiento frente a estos problemas. Como manifestaba La Nación, "Los hombres de trabajo y de negocios, los que desean emplear capitales o dedicarse a la explotación de nuestras riquezas, se hacen diariamente a sí mismos una serie de interrogantes cuya constatación es una incógnita" (La Nación, 25/7/1898). La preocupación por la definición de la cuestión limítrofe abarcaba todo el arco de opinión.

Para algunos sectores, principalmente ligados al comercio y a las finanzas, la guerra condicionaba la situación de crisis y la retracción de capitales. Para otros -como Silvio Gesell-, ${ }^{30}$ la crisis económica, producto de una moneda excesivamente valuada, producía el clima de guerra y enfrentamiento. Aunque opuestos, los dos argumentos coincidían en colocar en veredas distintas el progreso y la guerra. La expectativa sobre el mejoramiento de la economía con la nueva gestión estaba basada, en algún punto, en el respaldo que significaba internacionalmente la figura de Roca. El respaldo a su presidencia de sectores como "la alta cámara de comercio y finanzas" estaba dado tanto por la promesa de mantener la calma interna alcanzada como por la confianza en la figura de Roca como político y militar experimentado que sabe "los peligros y los desastres de las guerras internacionales" y en quien se confía que conservaría "la paz sin menoscabo de la dignidad de esta gran nación, que es demasiado fuerte para ser agredida y demasiado justa para agredir sin razón" ( $E l$ Correo Español, 26/8/1898). Así lo había expresado Robert Thurburn, ${ }^{31}$ como vocero de las aspiraciones de ese sector para su gestión, en el banquete con el que homenajearon a Roca en el Teatro Ópera luego de que ganara la presidencia ( $L a$ Voz de la Iglesia, 25 de agosto de 1898). Para este sector, un acuerdo de paz que evitara la guerra y posibilitara acabar tranquila y definitivamente la cuestión limítrofe era fundamental. Ésta fue la postura que Roca expresó en su discurso, en el que subrayó que "en las artes de la paz [se basan] el bienestar y la grandeza del país, afirmando que a ellas deben las brumosas Islas Británicas su poderío, su sensatez y sus libertades" (La Prensa, 1/9/1898). La guerra y el progreso económico estaban reñidos.

Sin embargo, esta opinión no era unánime. Otros sectores, como los relacionados con la Liga Patriótica expresados por su presidente Alfredo Lagarde-, ${ }^{32}$ preferían, por sobre el ejemplo de Inglaterra, el de Alemania que, siguiendo el impulso que había recibido después de 1870, con el triunfo en Sedan, invadía "todos los mercados del mundo y llega a despertar la rivalidad y hasta los recelos de aquella [Inglaterra], y lo debe tanto como al espíritu laborioso y progresista de su pueblo a su imponente y probada potencia militar" (La Prensa, $17 / 5 / 1898)$.

La creciente tensión diplomática entre la Argentina y Chile y los rumores de guerra, alentados desde el otro lado de la cordillera, encontraron mayor repercusión en una opinión pública expectante. En agosto, y de acuerdo con lo pautado en mayo, los peritos se reunieron en Santiago de Chile para acordar el criterio de 
demarcación limítrofe. Las negociaciones no tuvieron resultado, pues los peritos no se pusieron de acuerdo. Septiembre fue un mes de tensión, alerta pública y debate ya que, en cumplimiento con el tratado de 1881 y el protocolo firmado en 1896, se planteaba una opción entre la guerra y el arbitraje. El gobierno continuaba sin adelantar su postura frente a esta posible disyuntiva.

La creciente impaciencia pública dio lugar a un debate sobre cómo debía posicionarse el gobierno en relación con las negociaciones. Distintas voces intervinieron desde la prensa, las publicaciones (Quesada, 1898) y las conferencias. Entre estas destacaron, por su antimilitarismo y propensión expresa a la paz, las ligadas al Partido Socialista. Algunas de sus personalidades más representativas, como José Ingenieros, criticaron la guerra y también el papel del patriotismo militarista en la movilización de la sociedad (Reyes y Bacolla, 2018). En una posición diametralmente opuesta, Estanislao Zeballos, tanto desde la redacción de La Prensa como desde la recién fundada Revista de Derecho, Historia y Letras, (Zeballos, 1898), realizó un exhaustivo análisis sobre las condiciones para la guerra con Chile. ${ }^{33}$ Manuel Montes de Oca analizó la historia de las negociaciones enfocándose en el carácter de Barros Arana, ${ }^{34}$ con lo que confirmaba una corriente de opinión que le atribuía los problemas limítrofes. La misma Liga Patriótica, como entidad que buscaba interpretar los "hondos anhelos en la defensa tranquila del territorio nacional expuesto nuevamente a la desmembración" del pueblo argentino, se propuso incentivar la realización de conferencias (La Nación, 9/6/1898). En esos meses el debate público quedó atravesado por las múltiples aristas y soluciones que el conflicto desplegaba.

\section{ClímaX Y ANTICLÍMAX: LA NEgOCiaCión DE SEPTIEMBRE}

Durante las jornadas de septiembre, en vísperas de la firma de las actas surgieron desde distintos ámbitos iniciativas para realizar manifestaciones. Las subcomisiones de la Liga de las parroquias Piedad, Balvanera Norte y San Cristóbal fueron de las más activas y demandaron a la Junta Central que pusiera "en práctica los ideales y propósitos" con los que la Liga había sido fundada. Para hacer explícita su propuesta, invitaron a todos los ciudadanos a apersonarse frente a la Junta Central para demandarle su participación en el caso (La Nación, 19/9/1898). Este clima de movilización fue acompañado por manifestaciones estudiantiles en Tucumán y Salta, y también en la Capital Federal.

Hubo, de parte del gobierno, una reacción de prevención y alarma frente a las manifestaciones que, contrarias a la dirección en política exterior que estaba tomando, podían alterar el orden alcanzado en esos años. Probablemente por la temática de guerra, agitaron el fantasma de la revolución, haciendo que se las percibiera como peligrosas. Así, la policía decidió prohibir las manifestaciones y sólo permitirlas bajo permiso previo. En el último cuarto de siglo, las reglamentaciones policiales buscaron controlar aquellas derivas de las movilizaciones callejeras que se consideraba que podían alterar el orden. Esta atribución policial fue aplicada discrecionalmente y, en varios casos, puede ser leída como el límite oscilante entre lo que se consideraba el derecho a la expresión y la alteración del orden. ${ }^{35}$ Así, fueron suspendidas tanto las manifestaciones estudiantiles que buscaban organizar un "meeting de protesta contra el arbitraje general" ( $\mathrm{La}$ Prensa, 21/9/1898), como la concentración para peticionar a las autoridades de la Liga la celebración de un "meeting que exteriorice su presencia [del pueblo argentino] y demuestre el poder de sus fuerzas vivas, manifestando que la Liga Patriótica debe promover ese movimiento" (La Prensa, 22/9/1898). En este contexto, la movilización patriótica fue vista como peligrosa ya que ponía en cuestión varios temas en disputa. Por un lado, cuestionaba cuál era el significado del patriotismo y por el otro, evidenciaba las tensiones que la movilización albergaba y el peligro de que se tornara en contraria al accionar de la dirigencia. 


\section{1. Patriotismo y movilización}

A lo largo de 1898, el accionar de la Liga Patriótica puso en el centro del debate los valores asociados al patriotismo. El discurso que iba a pronunciar Belisario Roldán (hijo), como vocero de las comisiones parroquiales de la Liga Patriótica, en el suspendido meeting, subrayaba que el pueblo deseaba "la paz honrosa" y, si esa no fuera posible, la guerra, "para mantener el brillo, su emblema y tradiciones" (La Nación, 23/9/1898). La disyuntiva entre la deshonra y la guerra aparecía en la voz de los miembros de la Liga, de los estudiantes y de varios periódicos que abogaban por una guerra que defendiera los intereses de la Nación (Bertoni, 2001).

Este modo de entender la situación, como dilema, era parte del clima global del fin de siglo y remitía a los debates sobre la definición de Nación y su valoración en el concierto internacional. En agosto, La Prensa había reflexionado sobre esto a raíz de la situación de España en Cuba frente a los Estados Unidos y había felicitado a España por la actitud tomada al concurrir a una guerra que no había aceptado por "la empeñosa necesidad de vencer", ya que el enemigo la sobrepasaba en recursos, sino como una demostración del "carácter como fuente de recursos nacionales” (La Prensa, 14/8/1898). Las nociones de regeneración y reacción, que ya formaban parte del vocabulario político (Botana y Gallo, 1997; Alonso, 2000; Botana, 2005, pp. 119-136; Reyes, 2015, pp. 117-146), cobraron en el contexto del conflicto bélico mayor fuerza y le dieron un sentido programático al patriotismo, que era presentado como una opción para reparar la crisis y para engrandecer a la Nación.

En este uso, se perfilaron dos modos de entender el patriotismo y su papel en la política. Uno lo entendía como una causa, propia del Estado, a la que la sociedad debía concurrir en apoyo. Se acercaba a la propuesta de la nación como unidad cultural, en la que se integraban, bajo una "bandera común", la política del Estado y la autoridad popular. Al colocar el motor en la amenaza externa, la propuesta de la Liga Patriótica se mantenía en la cornisa, en una presentación prescindente del escenario interno, que no buscaba "contrariar las ideas sanas ni los actos honestos, ni los intereses legítimos", pero que a la vez solicitaba el concurso del patriotismo como "un auxiliar poderoso de los gobernantes que cumplen sus deberes, a quienes los rodeará la atmosfera vital de que desgraciadamente carece por causas notorias que es ocioso repetir" (La Prensa, 19/5/1898). Así, la causa patriótica le permitía convocar a "las fuerzas vivas intelectuales y cívicas de la República incitándolas a que la sirva en sus negocios de mayor gravedad, complementando o supliendo la acción de los poderes públicos". Como fuerza viva, se presentaba como "el elemento que debía ser inoculado en el espíritu yermo que dirige la nave del Estado" (La Prensa, 20/5/1898).

La Nación reaccionó contra este modo de entender la política, que identificaba con "una misión providencial, una intención cuasi divina que, reconocida, equivaldría a una infalibilidad que la convertiría en árbitro de los destinos públicos, en intendencia del patriotismo nacional; no restando a la opinión más papel que el de editor responsable de esas supremas inspiraciones" (La Nación, 20/5/1898). En esta contienda La Nación retomaba la idea de un patriotismo asociado a la virtud política -más cercano al republicanismo clásico que sintetizaba, en el lenguaje político de la segunda mitad del siglo XIX, un referente de las distintas formas de entender la buena conducta del ciudadano- ${ }^{36}$ y que dejaba "inviolable el recinto de la conciencia pública, que se expresa y exterioriza por otros medios y otros órganos que el de un comité". Así, se oponía a la existencia de una entidad que "infundida por las virtudes del patriotismo asumiera un pastorado patriótico, encargado de conducir los pueblos por el camino de su salvación” (La Nación, 20/5/1898).

En el contexto de tensión creciente por las negociaciones, en septiembre la Liga Patriótica emitió un comunicado en el que se pronunciaba en contra del arbitraje general para decidir el límite occidental y en favor del resguardo de la soberanía sobre los territorios patagónicos, y consideraba fuera de discusión el territorio de la Puna. Así, trascendía su papel en los "negocios de orden administrativo-militar, desenvueltos dentro del plan de organización adoptado por los Poderes Públicos” y se posicionaba políticamente. El mensaje contenía una serie de puntos sobre su postura en la negociación, en los que manifestaba como "inadmisible 
el arbitraje general sobre el principio de la demarcación del límite occidental de la república”, considerando que sólo era admisible en desacuerdos parciales, "de orden geográfico, y no de principios, sobre la ubicación de determinados valles transversales, situados dentro de la cordillera”. Al tiempo que se posicionó sobre qué política debía tomar el gobierno, exhortó al pueblo argentino "a organizar su influencia cívica de acuerdo con las ideas y soluciones expuestas y mantenidas en este documento". Proponía una misión patriótica que, aunque sometía a juicio del pueblo, consideraba que tenía que ser la del Estado (La Prensa, 4/9/1898). Así, se reforzaba una idea de patriotismo ligada a la causa común de defensa de la nación bajo la que movilizaba a la ciudadanía. La Liga no establecía límites a las negociaciones y señalaba la posibilidad de la guerra si la paz no era "honrosa". Esta valoración parecía nutrirse de términos parecidos a los que habían teñido el conflicto hispano-norteamericano, marcaba el punto de tensión del respaldo a las negociaciones del gobierno, quitándoselo si no era el adecuado, e indicaba una posible ruptura del consenso.

\subsection{Resistencias a los modos de hacer la paz: los límites del patriotismo}

El 22 de septiembre el gobierno argentino firmó la última de las cuatro actas que pusieron fin al conflictolas anteriores habían sido firmadas el 15 y 17 de ese mes- y que surgieron de la reunión entre el ministro plenipotenciario argentino en Santiago de Chile, Santiago Piñero, y el ministro de Relaciones Exteriores chileno, Juan Carlos Latorre. Las actas dividían la cuestión limítrofe en tres sectores, para ser discutidos por separado: la Puna de Atacama -comprendida entre los paralelos 23 y 26 de latitud sur-, la relativa al límite entre el paralelo 26 y el 52 y la relativa a la sección cercana al paralelo 52. Ante la falta de acuerdo entre los peritos, el acta del 17 de septiembre posponía el tratamiento de la cuestión de la Puna de Atacama. ${ }^{37}$ Las actas firmadas el 22 establecían las diferencias de los peritos en el trazado en la sección entre el paralelo 26 y el lago Viedma y la zona cercana al paralelo 52, y dictaban que, frente a ellas, se recurría al arbitraje de la reina Victoria de Gran Bretaña. ${ }^{38}$

Los acuerdos celebrados en septiembre orientaron las negociaciones lejos de los rumores de guerra y enfrentamiento pues se acordaba la paz. Esta resolución final pasmó a la opinión pública argentina, que fue "sorprendida con el relato telegráfico de la solución dada al litigio internacional" en las actas firmadas por el ministro de Relaciones Exteriores del Gobierno de Chile y el ministro argentino en Santiago, doctor Piñero, "que publicamos hoy como parte de las informaciones relativas a dicho asunto" (La Prensa, 24/9/1898). Frente a la promovida guerra, la opción por el acuerdo -tanto la firma de las actas como el arbitraje celebrado el año siguiente- provocó una crisis en las expectativas de la opinión, que se tradujo en una fractura del consenso sobre la figura de Roca como líder capaz de recomponer el orden y de posicionar al Estado argentino en América Latina.

El modo de finalización del conflicto impactó fuertemente en la opinión pública y en el patriotismo de guerra, que había crecido alrededor del enfrentamiento y demostrado gran capacidad de movilización. Este final exacerbó al máximo la polémica sobre cuál era el papel que les correspondía a sociedades como la Liga Patriótica, o la Asociación Patriótica Española, una vez acordada la paz, y volvieron a ponerse bajo escrutinio público las características y las cargas programáticas asociadas al patriotismo. Frente a la noticia de las actas firmadas con Chile, que ponían fin a la posibilidad de la guerra y abrían el camino al arbitraje, la Liga implosionó. La Junta Ejecutiva Central resolvió "aplazar sus reuniones ordinarias en que ha venido ejerciendo el mandato de condensar los esfuerzos de la opinión dominante de la República en los asuntos internacionales, para reanudar tan benéfica tarea cuando nuevos acontecimientos lo exijan”, pues consideró que ya no era necesario su concurso (La Prensa, 29/9/1898).

Esta resolución sorprendió a sus propias bases, que parecían defraudadas, y los motivos dejaron lugar a múltiples interpretaciones. Para La Nación era la evidencia de un aval a las condiciones en las que se había acordado el arbitraje, ya que la declaración misma de que la Liga volvería a ocupar su puesto "en el terreno 
de la acción y de la propaganda, si nuevas exigencias así lo determinasen, envuelve la afirmación de que las suposiciones recelosas ni se han cumplido, ni tendrían ya razón de ser”; o, como entendía el diario, que a juicio de la Liga "el arbitraje aceptado no tiene, de ninguna manera, un carácter discrecional, considerándose, con razón, que se halla estrictamente sujeto a las reglas de los tratados" (La Nación, 30/9/1898).

En cambio, La Prensa consideraba que habían terminado los momentos "de expectativa, de ansiedad, de dudas, respecto a las soluciones del más peligroso e inagotable de nuestros problemas nacionales", en los que era necesario "dar forma, disciplina y dirección a esa vastísima suma de fuerza libre". Sin embargo, no descartaba que las crisis continuaran "a medida que nuestra política de paz perpetua se va convirtiendo en un principio inmutable, en un hábito irrenunciable” (La Prensa, 30/9/1898). Probablemente La Prensa, al igual que la Liga, juzgaba difícil continuar con una amplia movilización una vez terminado el peligro de la guerra, sin enfrentarse al gobierno que había acordado los términos. Así, mientras la Liga suspendía sus acciones, que en el contexto crítico hubieran llevado a una alteración del orden, su vocero principal, La Prensa, continuaba el escrutinio de las condiciones de la paz. Es probable que una vez terminada abruptamente la situación, y no habiéndose producido -como sí había sucedido en el caso de la guerra hispano-norteamericana- una derrota que llevara a la reformulación de los valores y su exacerbación, la Liga no haya encontrado margen para realizar una reformulación de otro tipo de patriotismo, distanciado de las disputas partidarias, como el planteado por la Asociación Patriótica Española.

\section{Conclusiones}

En 1898, la aparición en la escena pública de la Liga Patriótica se dio en un clima de tensión y ansiedad política por la situación limítrofe con Chile y por la situación económica. La candidatura de Roca se había sostenido en la promesa de su capacidad para solucionar la situación; sin embargo, tanto en el contexto de su elección, en julio, como en el de su asunción, en octubre, esta promesa parecía haberse desvanecido. Frente a esta situación, distintos sectores juzgaron la situación del país como crítica y propusieron soluciones articuladas por el valor del patriotismo al que convocaban a la ciudadanía. A través de asociaciones esta apelación movilizó recursos económicos, mediante empréstitos y subscripciones, y buscó preparar a la nación para la guerra con ejercicios militares y prácticas de tiro. Como valor político que orientaba el comportamiento, el significado del patriotismo se puso en debate. En el fin de siglo, los actores disputaron sobre qué significaba actuar patrióticamente. Esta disputa estuvo relacionada con los modos de entender la nación y la identidad pero también, como buscamos analizar en este artículo, con modos de entender qué era lo legítimo y lo ilegitimo en el momento de intervenir públicamente. La situación de la posible guerra con Chile escenificó este debate y demostró la eficacia política del patriotismo -como valor político que orientaba el comportamiento- para aunar voluntades, congregar intereses y construir una unidad frente al peligro externo de la guerra. Los peligros del patriotismo exaltado fueron señalados por distintos sectores del arco político, que veían en éste un posible germen de disrupción del orden. El debate público quedó atravesado por llamamientos a la calma y denuncias del patriotismo militante (Reyes y Bacolla, 2018), al mismo tiempo que la Liga Patriótica mostró sus potencialidades para movilizar a la ciudadanía e intervenir en dicho debate.

La Liga Patriótica logró ocupar un lugar central en el debate público, proponiéndose como un canal de conexión entre la sociedad movilizada y el gobierno. El éxito de esta intervención radicó en entender la situación como crítica y en presentar esta intervención como una solución. A medida que se desenvolvía el conflicto, la Liga dio cuenta de la potencialidad para confrontar las políticas llevadas a cabo por el gobierno. La movilización patriótica presentaba una doble faceta que la convertía en un mecanismo de acción política exitoso. Por un lado, su potencialidad para aunar voluntades e intervenir en un escenario que se entendía como crítico, presentándose como parte de la solución. Con su conformación había buscado acompañar el accionar del gobierno y reforzar las políticas destinadas a armar a la ciudadanía y prepararse para la guerra. Por el otro, representaba un peligro para el orden establecido. Una vez movilizada la ciudadanía por la 
emergencia que presentaba la disyuntiva de sostener una paz honrosa o ir a la guerra, se abría el dilema de cómo desmovilizarla si el gobierno no se inclinaba por una de estas opciones. ¿¿Hasta dónde acompañar con su intervención en el debate público la acción propuesta? ¿Hasta dónde desafiar la acción del gobierno? En el contexto de firma de los tratados, y frente al silencio general sobre cómo se iba a actuar, la tensión entre estas dos posibilidades aumentó y se tradujo en una tensión entre las bases movilizadas y la dirigencia, que puso en crisis a la Liga.

Frente a la firma de los acuerdos, que no eran ni la paz honrosa ni la guerra, quienes dirigían la Liga optaron por desarmarla. Consideraron que, pasado el momento crítico, su propósito había llegado a un fin. En algún punto resolvieron la tensión optando por acompañar el accionar del gobierno y buscaron desactivar la potencialidad de la movilización patriótica, aunque dejando un clima de insatisfacción. Por otro lado, la desarticulación les permitió conservar el imaginario de unidad y evitar la fractura, que hubiera obligado a redefinir sus objetivos luego de la firma de los tratados. Este clima fue el que acompañó la asunción de Roca en octubre de 1898 y puso en jaque, desde su inicio, la promesa de recuperación de orden. De esta experiencia quedaba una práctica aprendida y la posibilidad latente de generar una unidad y movilización que podía ser capitalizada cuando se entendiera que el peligro había regresado, como finalmente ocurrió en 1901. El recrudecimiento del conflicto y del clima de crisis fue terreno fértil para desarrollar el potencial de intervención de este tipo de asociaciones. Algunos exmiembros, principalmente bajo la dirección de Estanislao Zeballos, se propusieron rearmarla; esta nueva experiencia quedó orientada por la coyuntura de la primera década del siglo XX

\section{Fuentes}

La Nación, 1898

La Prensa, 1898

La Voz de la Iglesia, 1898

El Correo Español, 1898.

Revista de Derecho, Historia y Letras, $\mathrm{N}^{\circ}$ 2, agosto de 1898.

Congreso Nacional/Diputados (1898). Diario de Sesiones del Honorable Congreso de la Nación, Cámara de Diputados. Buenos Aires: Imprenta del Congreso.

Moreno, F. (1897). Reconocimiento de la región andina de la República Argentina: apuntes preliminares sobre una excursión del Neuquén, Rio Negro, Chubut y Santa Cruz. La Plata: Talleres de Publicaciones del Museo.

Quesada, E. (1898). La politica argentina respecto a Chile. 1895-1898. Buenos Aires: Moen.

Zeballos, E. (1898). La reunión de los peritos. Revista de Derecho, Historia y Letras, № 2, 256-265.

\section{REFERENCIAS}

Alonso, P. (1997). En la primavera de la historia. El discurso político del roquismo de la década del ochenta a través de su prensa. Boletin del Instituto de Historia Argentina y Americana "Dr. Emilio Ravignani", No 15, Tercera Serie, $1^{\circ}$ semestre de 1997, 35-71.

Alonso, P. (1998). La reciente historia política de la Argentina del ochenta al centenario. Anuario IEHS, $\mathrm{N}^{\circ} 13$, 393-418.

Alonso, P. (2000). Entre la Revolución y las urnas. Los origenes de la Unión Cívica Radical y la política argentina en los años 90. Buenos Aires: Sudamericana-San Andrés.

Alonso, P. (Ed.) (2004). Construcciones impresas: panfletos, diarios y revistas en la formación de los Estados nacionales en América Latina. 1820-1920. Buenos Aires: FCE. 
Alonso, P. (2010). Jardines secretos, legitimaciones públicas. El Partido Autonomista Nacional y la politica argentina de fines del siglo XIX. Buenos Aires: Edhasa.

Alonso, P. (2015). La historia política y la historia de la prensa: Los desafíos de un enlace. En A. Pineda Soto (Coord.), Recorridos de la prensa moderna a la prensa actual (pp.11-34). México D. F.: Universidad Autónoma de Querétaro.

Balbi, F. (2008). De leales, desleales y traidores. Valor moral y concepción de politica en el peronismo. Buenos Aires: Antropofagia.

Bertoni, L. A. (1998). Acerca de patriotas y cosmopolitas en el cambio de siglo. Entrepasados, № 15, 189 -196.

Bertoni, L. A. (2001). Patriotas, cosmopolitas y nacionalistas. La construcción de la nacionalidad argentina a fines del siglo XIX. Buenos Aires: FCE.

Botana, N. (1977). El orden conservador. La politica argentina entre 1880 y 1916. Buenos Aires: Sudamericana.

Botana, N. (2005). El arco republicano del Primer Centenario: regeneracionistas y reformistas, 1910-1930. En J. Nun (Comp.), Debates de Mayo. Nación, cultura y politica (pp. 119-136). Buenos Aires: Gedisa.

Botana, N. y Gallo, E. (1997). De la República posible a la República verdadera (1880-1910). Buenos Aires: Ariel Historia.

Buonuome, J. (2019). Nuevas perspectivas en la historia de la prensa argentina. Investigaciones y ensayos, $\mathrm{N}^{\circ} 68,15-184$.

Camacho Arango, C. (2011). Síntesis y perspectiva de los estudios de transferencias militares europeas en Suramérica (1890-1940). Hlb. Revista de Historia Iberoamericana, 4(12), 40-58.

Carey, C. (2016). Breaking the news. Telegraphy and yellow journalism in the Spanish-American war. American Periodicals, 26(2), 130-148.

Castro, M. (2012). El ocaso de la república oligárquica. Poder, política y reforma electoral. 1898-1912. Buenos Aires: Edhasa.

Cucchi, L. y Dapelo, L. (coords) (2016). La política en las provincias durante la emergencia y consolidación del Partido Autonomista Nacional. Coordenadas. Revista de Historia Local y Regional, vol. 3, 84-93.

Cucchi, L. y Rojkind, I. (Coords.) (2017). Dossier Oligarquía, república y democracia: Debates sobre la vida política en la Argentina del Orden Conservador. Investigaciones y Ensayos, $\mathrm{N}^{\circ}$ 65, 29-178.

Cucchi, L., Polastrelli, I. y Romero, A. L. (2020). Construir y limitar el poder en la república del siglo XIX. En H. Sabato y M. Ternavasio (Coords.), Variaciones de la república: la politica en la Argentina del siglo XIX. (pp. 59-78) Rosario: Prohistoria.

Di Meglio, G. (2008). Patria. En N. Goldman (Ed.), Revolución y lenguaje. Conceptos políticos clave en el Río de la Plata, 1780-1850 (pp. 115-130). Buenos Aires: Prometeo.

Di Stefano, R y Zanatta, L. (2015). Historia de la Iglesia argentina: de la conquista al siglo XXI. Buenos Aires: Sudamericana.

Espinosa Moraga, O. (1958). La postguerra del Pacífico y la Puna de Atacama, 1884-1899. Santiago de Chile: Editorial Andrés Bello.

Ferrari, G. (1968). Conflicto y paz con Chile (1898-1903). Buenos Aires: EUDEBA.

Fraga, R. (1996). La amistad Roca-Riccheri a través de su correspondencia. Buenos Aires: Círculo Militar.

Furet, F. (1995). El pasado de una ilusión. Ensayo sobre la idea comunista en el siglo XX. México: FCE.

Gerchunoff, P., Rocchi, F. y Rossi, G. (2008), Desorden y progreso. Las crisis económicas argentinas 1870-1905. Buenos Aires: Edhasa.

Goldenberg, B. (2000). Imperial Culture and national conscience: the role of the press in the United States and Spain during the crisis of 1898. Bulletin of Hispanics Studies, LXXVII(3), 169-191.

Lacoste, P. (2001). Chile y Argentina al borde de la guerra (1881-1901). Anuario del CEH, N 1, 301-328.

Lacoste, P. (2003). La imagen del otro en las relaciones de la Argentina y Chile (1534- 2000). Buenos Aires: FCE.

McGee Deutsch, S. (2001). Contrarrevolución en la Argentina, 1900-1932: la Liga Patriótica Argentina. Buenos Aires: Manantial. 
Mosse, G. (2007). La nacionalización de las masas. Simbolismo politico y movimientos de masas en Alemania desde las guerras napoleónicas hasta el Tercer Reich. Buenos Aires: Siglo XXI.

Olarra Jiménez, R. (1980). Las reformas monetarias (1880-1910). En E. Gallo y G. Ferrari (Comps.). La Argentina del Ochenta al Centenario (pp. 513-528), Buenos Aires: Sudamericana.

Paredes, R. (2011). Estanislao Zeballos canciller: entre la diplomacia cultural y la guerra modera (1878-1908). En S. Fernández y F. Navarro F. (Comps.), Scribere est agere. Estanislao Zeballos en la vorágine de la modernidad argentina (pp. 105-122). Rosario: La Quinta pata \& Camino ediciones.

Reyes, F. (2015). La revolución como mito, la regeneración como promesa. Ideas-fuerza en los orígenes de la Unión Cívica Radical. Ariadna histórica. Lenguajes, conceptos, metáforas, $\mathrm{N}^{\circ}$ 4, 117-146.

Reyes, F. (2016a). De la velada de club a la estética de los cortejos. La construcción del $1^{\circ}$ de Mayo socialista en la Argentina finisecular (1894-1900). Boletín del Instituto de Historia Argentina y Americana "Dr. Emilio Ravignani", $\mathrm{N}^{\circ} 44,42-77$.

Reyes, F. (2016b). Conmemorar la Revolución y sus mártires. Ritual político e identidad en los orígenes del radicalismo (1891-1897). Estudios sociales, $\mathrm{N}^{\circ}$ 50, 41-76.

Reyes, F. (2018). La patria es el otro, pero no para siempre. La cuestión de la nación en el socialismo de la Argentina finisecular (1894-1912). Historia y Politica, $\mathrm{N}^{\circ} 39,203-234$.

Reyes, F. y Bacolla, N. (2018). Los socialistas argentinos ante el conflicto chileno-argentino. Formas y sentidos del antimperialismo. En los orígenes del Partido Socialista en Argentina (1894-1902). Iberoamericana, XVIII(68), 201-226.

Rocchi, F. (2006). Chimneys in the Desert: Argentina During the Export Boom Years, 1870-1930. Stanford: Stanford University.

Rock, D. (2006). La construcción del Estado y los movimientos políticos en la Argentina, 1860-1916. Buenos Aires: Prometeo Libros.

Rojkind, I. (2008). El derecho a protestar. Diarios, movilizaciones y politica en Buenos Aires del novecientos, (Tesis doctoral inédita, Colegio de México: Centro de Estudios Históricos). Recuperada de https://colmex.userservic es.exlibrisgroup.com/view/delivery/52COLMEX_INST/1264710810002716

Rojkind, I. (2012). El gobierno de la calle. Diarios, Movilizaciones y política en el Buenos Aires del novecientos. Secuencia. Revista de historia y ciencias sociales, $\mathrm{N}^{\circ} 84,99-123$.

Rojkind, I. (2017). Campañas periodísticas, movilizaciones callejeras y críticas al gobierno. La participación política en el orden conservador. Investigaciones y Ensayos, $\mathrm{N}^{\circ} 65,113-134$.

Rojkind, I. (2019). El diario La Prensa en el cambio de siglo: modernización periodística y batallas políticas. Investigaciones y ensayos, $\mathrm{N}^{\circ} 68,55-79$.

Roldán, D. (2005). Ocio y patriotismo. Configuraciones de sentido a través de la práctica del tiro, Rosario 1890-1920. En M. Bonaudo Imaginarios y prácticas de un orden burgués. Rosario 1850-1930. Los actores entre las palabras y las cosas (pp. 173-198), Rosario: Prohistoria.

Romero, A. L. (2007). La política del patriotismo. La conformación de la Asociación Patriótica Española (1896-1898). Estudios Migratorios Latinoamericanos, № 64, 457-484.

Romero, A. L. (2008). (Edición y presentación). A treinta años de El orden conservador. Un Dossier sobre un clásico de la historia política. Boletín Bibliográfico Electrónico. Publicación semestral del Programa Buenos Aires, № 2, 7-8. Recuperado de: http://www.polhis.com.ar/index.php/polhis/issue/archive.

Romero, A. L. (2018). Crisis y transición: Notas sobre el fin de siglo argentino. Pasado Abierto, $\mathrm{N}^{\circ}$ 7, 241-251. Recuperado de: https://fh.mdp.edu.ar/revistas/index.php/pasadoabierto/article/viewFile/2595/2745.

Sabato. H. (1998). La política en las calles, entre el voto y la movilización. Buenos Aires, 1862-1880. Buenos Aires: Sudamericana.

Yujnovsky, I. (2011). El debate en torno a un relato de viajes y el conflicto sobre la frontera argentino-chilena a fines del siglo XIX. Estudios Trasandinos, 16 (1), 96-113. 
Zimmermann, E. (1998). La prensa y la oposición política en la Argentina de comienzos de siglo: el caso de "La Nación” y el Partido Republicano. Estudios Sociales, 15 (1), 45-70.

\section{Notas}

1 La caracterización del período proviene de una lectura generalizada, y a veces acrítica, del libro de Natalio Botana (1977). En los últimos años, varios autores han puesto en debate la caracterización de Botana sobre el período y las lecturas sobre este. Sobre el debate historiográfico y otras perspectivas, ver entre otros: Alonso, 1998; Alonso, 2000; Alonso, 2010; Castro 2012; Cucchi y Dapelo, 2016; Cucchi y Rojkind, 2017.

2 La situación económica suscitó al año siguiente, 1899, varias movilizaciones. Sobre ellas, ver Rojkind, 2008, pp. 94-124. Sobre la relación entre los meetings y la política económica del gobierno, ver Rocchi, 2006.

3 La cuestión limítrofe con Chile, que se mantenía en un statu quo desde el tratado de 1881, retomó importancia a principios de la década de 1890. Dos principios que habían quedado ambiguamente establecidos en el tratado estaban en disputa: el de las "altas cumbres", que beneficiaba a la Argentina, y el de la "divisoria de aguas", que favorecía más a Chile. En 1893 se firmó el Protocolo Adicional, que integraba ambos criterios: la frontera pasaría por aquellas altas cumbres que dividieran aguas; la Argentina no podría aspirar a puntos sobre el Océano Pacífico y tampoco Chile sobre el Atlántico. Ese mismo año se ratificó y ejecutó el Tratado Vaca Guzmán-Quirno Costa -firmado en 1889-, que estipulaba el intercambio de territorios entre Bolivia y la Argentina. La Argentina cedía Tarija e incorporaba la Puna, la que incluía un conflicto limítrofe con Chile. El protocolo de 1896 establecía que los gobiernos recurrirían al arbitraje como un modo de buscar acelerar las tareas de demarcación. Ferrari, 1968; Lacoste, 2001, pp. 301-328; Lacoste, 2003.

4 Luego de los acuerdos con la Casa Baring, el gobierno restringió la circulación de dinero con el objeto de valorizar el papel moneda. Esto produjo entre 1896 y 1899 una valorización del papel moneda que afectó los ingresos del sector agroexportador. Ante esta situación se discute, desde 1898, la posibilidad de establecer una ley de conversión monetaria que establezca un cambio fijo. La ley se sancionó en 1899. Olarra Jiménez, 1980; Gerchunoff, Rocchi y Rossi, 2008, pp. 276-279.

5 A finales del siglo XIX se redefinió el papel que la prensa cumplía en la esfera pública. En este proceso convergieron distintas variables, como la masificación del público lector, la modernización tecnológica en la producción del diario y la disputa por cuál era su papel en la sociedad. Este pasaje implicó también un cambio en el modo en que se concebía su intervención en el espacio público, de una prensa intervencionista y activa en la vida pública a un diario que se presenta ajeno a los acontecimientos. Alonso, 2004; Alonso, 2015; Buonuome, 2019.

6 Cuando el 15 de febrero de 1898 estalló en la costa cubana el acorazado norteamericano Maine, la prensa de ese país acusó rápidamente a España de la explosión y arengó en pos de la guerra. Como ha sido señalado, el New York Journal, de William Randolph Hearst, y el New York World, de Joseph Pulitzer, impulsaron activamente la guerra y construyeron la legitimidad del enfrentamiento, señalando tanto la tiranía española sobre la isla como el papel que debían cumplir los Estados Unidos como imperio en expansión. Ver Carey, 2016; Goldenberg, 2000.

7 Un análisis de la distinción entre ambos significados de patriotismo, en Furet, 1995; Bertoni, 1998.

8 Tomo la idea de valor moral trabajada por Balbi, 2008, entendiéndolo como un elemento definido en la interacción social con aspectos cognitivo, emotivo y moral, y que es utilizado por los actores tanto para juzgar las conductas como para entender la realidad.

9 La Liga Patriótica surgida en 1898 se desarticuló ese mismo año. La bibliografía se ha concentrado en el movimiento patriótico que surgió a finales del 1901 - de hecho, la de 1901 se llama Liga Patriótica Nacional- y que se vincula al movimiento de la década del 20, cuando toma el nombre de Liga Patriótica Argentina; este es el caso de los trabajos de Sandra McGee Deutsch (2001). Otros autores, como David Rock (2006, pp. 265-276), señalan también esta continuidad y la consideran antecedente de la política de masas y de las movilizaciones nacionalistas del siglo XX. Sobre La Liga Patriótica de 1898, ver Bertoni, 2001, pp. 238-242; Reyes y Bacolla, 2018, p. 208; Castro, 2012, pp. 59-63.

10 Francisco P. Moreno (Buenos Aires 1852- ídem 1919). Director del Museo de La Plata entre 1884 y 1905. Se desempeñó como perito argentino en el conflicto con Chile desde 1897. El libro en cuestión había sido elaborado antes de su designación y era el resultado de un de informe realizado por colaboradores del Museo que él convirtió en un relato de viaje. Sin embargo, el libro fue publicado luego de que fuera designado, lo que desató la polémica por considerar fraude su intento de demostrar empíricamente que los criterios de división de aguas y altas cumbres no coincidían. Moreno, 1897. Sobre esto, ver Yujnovsky, 2011.

11 Diario fundado en José C. Paz en 1869. Sobre La Prensa, ver Rojkind, 2008, 2019.

12 Diario fundado por Bartolomé Mitre en 1870. Sobre su articulación con la política, ver Zimmermann, 1998.

13 Carlos Pellegrini a Miguel Cané, Buenos Aires, 23 de febrero de 1898. Archivo General de la Nación. Fondo Cané. 
14 Para el papel de la movilización política en el fin de siglo, ver Sabato, 1998; Rojkind, 2012; Reyes, 2016a; Cucchi, Polastrelli, Romero (2020).

$15 \mathrm{La} \mathrm{Voz} \mathrm{de} \mathrm{la} \mathrm{Iglesia} \mathrm{fue} \mathrm{fundado} \mathrm{en} 1882$ en el contexto del debate por las leyes laicas y estuvo estrechamente ligado a los intereses de la curia en Buenos Aires. Ver Di Stefano y Zanatta, 2015. Sobre la coincidencia, ver La Voz de la Iglesia, $12 / 2 / 1898$.

16 En julio de 1892 la UCR también había iniciado una colecta similar para comprar un buque, subrayando su perfil menos conflictivo y en pos de los intereses de la nación. Ver Reyes, 2016b, p. 7.

17 Club Gimnasia y Esgrima a Dardo Rocha, Buenos Aires 14 de marzo de 1898. Archivo General de La Nación. Fondo Rocha.

18 Antonio del Pino (Tinogasta, Catamarca, 1855-Buenos Aires, 1916). Fue diputado nacional y senador por la provincia de Catamarca. En 1898 fue presidente del Club GEBA. Sobre los miembros de GEBA, ver La Nación, 8/3/1898.

$19 \mathrm{La}$ ley de presupuesto sancionada en 1897 avaluaba los recursos en 33.492 .000 pesos oro y 61.835 .000 peso moneda nacional. La Prensa, 6/4/1898. El Correo Español, 8/5/1898.

20 En la reunión fueron nombradas sus autoridades. Presidente: Ricardo Lavalle. Vicepresidente: Felix Bernal. Vicepresidente segundo: Manuel A. Montes de Oca. Secretarios: Felipe del Viso, Vicente Gallo, Arturo Canovio. Tesoreros: Carlos Zuberbuhler, Alberto de Gainza. Vocales: Ignacio Oyuela, Tomas de Anchorena, Carlos Torcuato de Alvear, Luis Huergo, Modesto Sanchez Viamonte, Faustino Jorge, Gregorio Aráoz Alfaro, Domingo Muga, Alejandro Paz, Ezequiel P. Paz, Alfredo Lagarde, José Fidel Lagos, Enrique Bazterrica, Carlos Agote, Carlos Estrada. La Nación, 3/4/1898.

21 Liga Patriótica a Dardo Rocha, La Plata, 28 de mayo de 1898. Archivo General de La Nación, Fondo Rocha.

22 Nuevas autoridades de La Liga Patriótica: presidente Ricardo Lavalle; vicepresidente $1^{\circ}$ José M. Gustavino; vicepresidente $2^{\circ}$ Alfredo Lagarde; secretarios Felipe R. Del Viso, Alejandro J. Paz, Arturo Canovi; tesorero Domingo Murga; protesorero Modesto Sánchez Viamonte; vocales Alberto Gainza, Luis A. Huergo, Faustino J. Jorge, Carlos A Estrada, José C. Soto, Pedro Agote, Roque Sáenz Peña, Emilio Lamarca, Mariano Varela, Rafael Pereira Ximenez, Joaquín Montaña, Rafael A. Cobo, José Ayerza, Daniel M. Escalada, José M. Ramos Mexía, José C. Paz, Ricardo Aldao, José A. Esteves, Francisco Reynolds, Estanislao Zeballos, Vicente Casares, José Fidel Lagos, Gabriel Giralt, Manuel A. Montes de Oca, Délfor del Valle, Ventura Martínez, Román Pacheco, Enrique A. de Toledo, Tomas E. de Anchorena, Mariano Demaría. La Nación, 23/7/1898.

23 La Prensa, 3/6/1898. La Nación, 9/6/1898. La Nación, 1/7/1898. En su viaje a Alemania de 1889 para comprar armamentos, Riccheri pidió modificaciones del modelo 1889 y se produjo el Mauser Argentino en 1891. Los 43.000 fusiles que compró fueron los utilizados por el Ejército hasta su remplazo por el modelo Mauser 1909. La preocupación por la instrucción en tiro convocó la atención del gobierno y de la sociedad civil en distintas ocasiones. En 1891 se fundó el Tiro Federal Argentino, organizado efectivamente en 1895 (Bertoni, 2001, pp. 219-238). Sobre el papel de los tiros federales en Rosario, ver Roldán (2005). Sobre la compra de armamentos, ver Camacho Arango (2011, p. 51), Fraga (1996, p. 57).

24 Roque Sáenz Peña, julio de 1898. Academia Nacional de Historia. Archivo Sáenz Peña. Libro copiador.

25 En agosto, La Liga Patriótica de San Luis solicitó a la Liga que la secundase con su influencia para obtener una parte de la suma votada por el Congreso para fomentar las instituciones de tiro. La Nación, 18/8/1898.

26 La Liga Patriótica nombró una comisión compuesta por Esteves y Lagarde y el Sr. Arturo Canovi para investigar las denuncias sobre el mal estado del cuartel de Maldonado, que alojaba mil hombres de artillería. También, sobre la situación del de Cuyo. La Nación, 1 de julio de 1898. La Nación, 26 de julio de 1898.

27 Proyecto presentado por el señor vocal D. José Soto, La Nación, 26/7/1898.

28 Los temores provenían de sectores diversos, como los ligados a la Iglesia o al socialismo. La Voz de la Iglesia, "Militarismo pernicioso", 19 de julio de 1898. Sobre la crítica a la militarización desde el socialismo, ver Reyes y Bacolla, 2018.

29 Este proyecto fue debatido entre junio y julio de 1898 (Congreso Nacional/Diputados, 1898, p. 366). Este punto también había justificado el aumento impositivo; ver, por ejemplo, Congreso Nacional/Diputados, 1898, p. 174.

30 Silvio Gesell (Bélgica 1862-Alemania 1930). Se radicó en Buenos Aires en 1887; tras la crisis económica de 1889 comenzó a estudiar el sistema monetario y desde 1891 publicó sus análisis y propuestas. Sus trabajos fueron retomados por John M. Keynes en la década de 1930 (Rocchi, 2006).

31 Robert Thurburn nació hacia 1850 en Portsoy, Escocia. En la Argentina vivió en Rosario y en Lomas de Zamora. En Buenos Aires fue director del Banco de Londres, Buenos Aires y el Río de la Plata. En 1910 ascendió a la Gerencia central.

32 Alfredo Lagarde (c. 1875-1911) se graduó como médico en 1887. Dos años antes publicó en los Anales del Círculo Médico el texto "La cocaína", que incluye la primera referencia en la Argentina a Sigmund Freud. Especializado en cirugía ginecológica, en 1891 realizó la primera operación cesárea exitosa y fue designado director de la primera Maternidad Municipal. En 1891 participó del grupo fundador de la Sociedad Médica Argentina (redenominada en 1913 como Asociación Médica Argentina). Consagrado a su profesión y a la formación de las parteras, en 1909 se sumó al grupo promotor de la candidatura presidencial de Roque Sáenz Peña. 
33 Sobre la postura de Zeballos y sus intervenciones en relación con la posición internacional de la Argentina, ver Paredes (2011).

34 Diego Barros Arana (Santiago de Chile, 1830-ídem1907). Intelectual chileno. En 1873 fue designado ministro plenipotenciario para negociar las cuestiones limítrofes con la Argentina. Montes de Oca, Manuel A. "Cuestión de límites", en La Nación, $1^{\circ}$ de agosto de 1898.

$35 \mathrm{Al}$ calor de coyunturas álgidas, se presentaron también en el Congreso varios proyectos para su reglamentación. Ver González Alemán, 2011. Sobre la tensión política, ver Cucchi, Polastrelli, Romero (2020).

36 Para el uso de la noción de patriotismo en relación con diferentes concepciones históricas, ver Di Meglio, 2008; Botana y Gallo, 1997.

37 El 2 de noviembre se firmaron dos actas sobre el problema de la Puna y se convocó a una conferencia de notables para saldar el debate; si no se lo lograba, se proponía ir al arbitraje. La conferencia se celebró en Buenos Aires en marzo de 1899 y no resolvió el problema. Este fue resuelto por la Comisión demarcadora, integrada por William I. Buchanan, Enrique Mac Iver y José Evaristo Uriburu, que determinó el trazado de la frontera. La resolución dividió a la opinión pública en ambos países. Muchos chilenos criticaron la entrega de la Puna, y en la Argentina hubo opiniones, como la de Zeballos, que consideraban desfavorable el fallo (Ferrari, 1968, pp. 24-27).

38 Los pliegos con la información para que la reina Victoria realizara el arbitraje fueron entregados entre noviembre de 1898 y febrero de 1899. El arbitraje se realizó entre marzo y julio de 1899. 